\title{
A Nitric Oxide Synthesis Inhibitor Prevents the ACTH- Stimulated Production of Aldosterone in Rat Adrenal Gland
}

\author{
TOMOHIRo NAKAYAMA, Yoichi IZUMI, MASAYoshi SOMA and KaTSUo KANMATSUSE \\ Second Department of Internal Medicine, Nihon University School of Medicine, Tokyo 173, Japan
}

\begin{abstract}
The synthesis of nitric oxide (NO) has been demonstrated in the vascular endothelial cells and other tissues including in rat and bovine adrenal gland. To determine whether NO mediates aldosterone production in the adrenals, we evaluated the basal production of aldosterone, and the ACTH or angiotensin II (A II)-stimulated aldosterone in the presence of L-N ${ }^{G}$ monomethyl arginine (L-NMMA) or L-arginine or L-NMMA + L-arginine in isolated rat adrenal capsular tissue by an $e x$ vivo perfusion technique. ACTH increased the release of aldosterone by $40 \%$. Such release of aldosterone was inhibited by L-NMMA, but not by a mixture of L-NMMA and L-arginine. A II stimulated aldosterone release by $40 \%$. The increase in aldosterone release in response to A II was inhibited by L-NMMA or Larginine. The increase in aldosterone release stimulated by A II was also inhibited by L-NMMA with L-arginine. L-glutamine did not inhibit the A II stimulated aldosterone release. In conclusion, the inhibition of NO synthesis prevented the release of aldosterone stimulated by ACTH, suggesting NO is required for the action of $\mathrm{ACTH}$ on aldosterone production.
\end{abstract}

Key words: Nitric oxide, Aldosterone, Adrenal gland, Perfusion, ACTH

(Endocrine Journal 43: 157-162, 1996)

NITRIC oxide (NO) is a ubiquitous intercellular messenger synthesized from the amino acid L-arginine by various isoforms of NO synthase (NOS) in different tissues. NO stimulates soluble guanylate cyclase to produce cGMP, and this in turn may stimulate the intracellular pathway. There are two isoforms of NOS that are classified by the expression of the enzymes. Constitutive NOS (cNOS)s are present in the cerebellum [1], the anterior cerebrum [2], the peripheral nerves [3] and the vascular endothelial cells [4-6], and share common biochemical and pharmacological features. And, inducible NOS (iNOS) is produced de novo by a stimulation as cytokine in the macrophages [7-9], the neutro-

\section{Received: April 18, 1995}

Accepted: November 13, 1995

Correspondence to: Dr. Tomohiro NAKAYAMA, The Second Department of Internal Medicine, Nihon University School of Medicine, Ooyaguchi, Kamimachi 30-1, Itabashi-ku, Tokyo 173, Japan phil [10], the endothelial cells [11] and other tissues.

It has recently been shown that $\mathrm{L}$-arginine and both the NOS inhibitors L-NG-monomethyl arginine (L-NMMA) and $\mathrm{L}^{-} \mathrm{N}^{\mathrm{G}}$-nitro arginine (L-NNA) stimulate pancreatic islet insulin release in vitro, but L-NNA did not stimulate insulin release in the perfused pancreas [12]. Furthermore, Kato showed that GH-releasing hormone (GHRH)-induced GH secretion was augmented by L-NMMA in rat pituitary cells, and suggested that GHRH stimulated the synthesis of NO at least partly through cAMP, thereby partially inhibiting GHRH-induced GH secretion [13].

Palacios et al. [14] identified L-arginine: NO synthase in rat and bovine adrenal glands and its stimulation of the production of soluble guanylate cyclase and guanosine 3', 5'-monophosphate (cyclic GMP) production. Although neuronal cNOS mRNA [15] and endothelial cNOS mRNA [16] were expressed in adrenal glands, immunohisto-chemi- 
cal reactivity of neuronal cNOS was not localized to rat adrenal capsular layers [17].

L-NMMA was reported to increase the serum corticosterone level in rats [18], and L-arginine administration decreases the serum aldosterone level in man [19]. The role of the NO-NOS system in aldosterone production has not been fully elucidated. To demonstrate that NO or NO-induced cyclic GMP mediates aldosterone production in the adrenal gland, we determined the aldosterone production stimulated by ACTH or angiotensin II (A II) in the perfused adrenal capsular tissue after the administration of L-arginine or L-NMMA.

\section{Materials and Methods}

\section{Materials}

Synthetic ACTH (1-24) and L-arginine were obtained from Daiichi Pure Chemical Co., Ltd. (Tokyo, Japan). A II and L-glutamine were purchased from Sigma Chemical Co., Ltd. (St. Louis, MO). L-NMMA was obtained from Ajinomoto Co., Inc. (Tokyo, Japan).

\section{Animals}

Nine-week-old male Wistar rats $(300-350 \mathrm{~g})$ were housed at a constant temperature of $24{ }^{\circ} \mathrm{C}$ and under artificial light ( $12 \mathrm{~h}$ of light; i.e; lights on from 0600 to $1800 \mathrm{~h}$ ). They received a diet containing a normal level of sodium $0.26 \%$ and potassium $0.85 \%$ and water ad libitum.

\section{Perfusion technique}

The animals were killed by decapitation. The adrenal glands were quickly removed and separated into the capsular and non-capsular portions. The capsular portions (mainly the zona glomerulosa) were bathed in Krebs-Ringer bicarbonate glucose albumin buffer (KRBGA). This buffer contained $119 \mathrm{mM} \mathrm{NaCl}, 25 \mathrm{mM} \mathrm{NaHCO}, 4.7 \mathrm{mM}$ $\mathrm{KCl}, 1.2 \mathrm{mM} \mathrm{KH} \mathrm{PO}_{4}, 1.2 \mathrm{mM} \mathrm{MgSO}$, $2.7 \mathrm{mM}$ $\mathrm{CaCl}_{2}, 11 \mathrm{mM}$ glucose and $0.2 \%$ bovine serum albumin. The perfusion system was previously described [20]. The KRBGA was gassed continuously with a $95 \% \mathrm{O}_{2}-5 \% \mathrm{CO}_{2}$ mixture, adjusted to $\mathrm{PH} 7.4,37^{\circ} \mathrm{C}$, and pumped at a flow rate of 0.2 $\mathrm{ml} / \mathrm{min}$. One capsular portion was cut into four pieces and applied onto a column. After $30 \mathrm{~min}$ of perfusion to achieve wash out and stabilization, effluents were collected every $10 \mathrm{~min}$ for the determination of aldosterone. The sample to which no agents were added to the KRBGA throughout the experiment was used as the control. After a 20-min baseline sampling, the tissue was superfused with L-NMMA $(100 \mu \mathrm{M}), \mathrm{L}$-arginine (300 $\mu \mathrm{M})$, or L-NMMA $(100 \mu \mathrm{M})$ with L-arginine (300 $\mu \mathrm{M})$ dissolved in KRBGA for $60 \mathrm{~min}$. After the tissues were superfused with L-NMMA $(100 \mu \mathrm{M})$, L-arginine $(300 \mu \mathrm{M})$, or L-NMMA $(100 \mu \mathrm{M})$ with L-arginine $(300 \mu \mathrm{M})$ containing KRBGA for $30 \mathrm{~min}$, ACTH $\left(10^{-8} \mathrm{M}\right)$ or A II $\left(5 \times 10^{-8} \mathrm{M}\right)$ was added to each medium for $30 \mathrm{~min}$ to investigate the effect of L-NMMA, L-arginine and L-NMMA with L-arginine on the stimulation of aldosterone production by ACTH and A II. To investigate the specific effects of amino acids on the stimulation of aldosterone production by A II, L-glutamine $(300 \mu \mathrm{M})$ was used instead of L-arginine.

\section{Analytical methods}

Levels of aldosterone in the medium were determined with a SPAC-S RIA Kit (Daiichi Pure Chemical Co., Ltd. Tokyo, Japan) [21]. The protein content in the adrenal gland was determined according to Lowry et al. [22].

\section{Statistical analysis}

Values are presented as the means \pm SEM. Oneway analysis of variance was used for statistical analysis. Student's $t$-test was used as appropriate. A level of $P<0.05$ was considered statistically significant.

\section{Results}

Aldosterone concentrations in the effluent KRBGA medium after baseline stabilization collected from the perfused rat adrenal gland were $177 \pm 56$ $\mathrm{pg} / \mathrm{mg}$ protein $/ \mathrm{min}$. The release of aldosterone after baseline stabilization did not differ significantly between all groups.

The release of aldosterone in the control group decreased gradually during the period of observation, as shown in Fig. 1. Neither L-NMMA (100 $\mu \mathrm{M})$ nor L-arginine (300 $\mu \mathrm{M})$ affected the release 
of aldosterone over the six fractions vs. control. LNMMA $(100 \mu \mathrm{M})$ with L-arginine $(300 \mu \mathrm{M})$ tended to reduce the release of aldosterone with significant differences apparent at 20-30 min vs. control.

ACTH $\left(10^{-8} \mathrm{M}\right)$ stimulated the release of aldosterone from the $50 \mathrm{~min}$, and significantly stimulated it for a period of 60-70 min (Fig. 2). This ACTHstimulated release of aldosterone was inhibited by L-NMMA $(100 \mu \mathrm{M})$, but not by L-arginine $(300 \mu \mathrm{M})$ alone, or by L-NMMA (100 $\mu \mathrm{M})$ with L-arginine (300 $\mu \mathrm{M})$.

As shown in Fig. 3, A II $\left(5 \times 10^{-8} \mathrm{M}\right)$ stimulated the release of aldosterone over the four fractions during its addition. This response was earlier than that of ACTH caused by an 1 fraction ( $10 \mathrm{~min}$ ). The increase in the release of aldosterone in response to A II was inhibited by L-NMMA (100 $\mu \mathrm{M})$ and L-arginine $(300 \mu \mathrm{M})$. There was no significant difference in these two groups as compared with the control throughout the experiment. The increase in aldosterone release in response to A II was also inhibited by L-NMMA $(100 \mu \mathrm{M})$ with Larginine $(300 \mu \mathrm{M})$ after the significant inhibition of aldosterone release by L-NMMA with L-arginine. A II stimulated the release of aldosterone in the presence of L-glutamine ( $300 \mu \mathrm{M})$, showing significant differences in a 50-70 min period.

\section{Discussion}

The increase in aldosterone release caused by ACTH in our experiment was inhibited by LNMMA, but not by L-NMMA with L-arginine, which indicates that the NO system in the adrenal glomerular layer is involved in the production of aldosterone via ACTH. There are at least two pathways of aldosterone release via ACTH. One is via cyclic AMP, and the other is via $\mathrm{Ca}^{2+}[23]$. The former is affected by a pharmacologic dose of ACTH (more than $10^{-9} \mathrm{M}$ ) while the latter is affected by a physiological concentration of ACTH (less than $10^{-10} \mathrm{M}$ ). The dose of $10^{-8} \mathrm{M}$ of ACTH in our experiment stimulated adenyl cyclase and cyclic AMP. McFarland et al. [24] reported that cyclic GMP-stimulated phosphodiesterase mediated the ANP-induced decreases in the production of cyclic AMP and aldosterone. Therefore in the adrenal NO system, some factor, perhaps NO rather than cyclic GMP, may stimulate the cyclic AMP pathway. Alternatively, basal levels of NO may

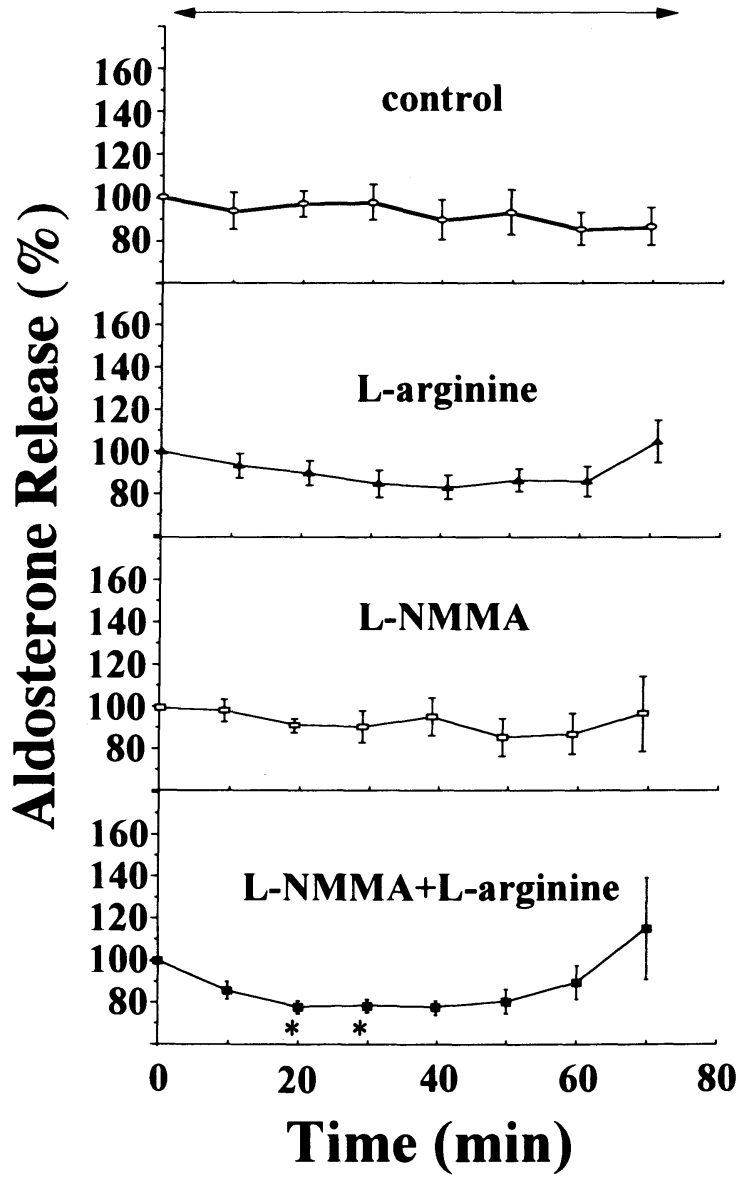

Fig. 1. Effects of L-arginine, L-NMMA and L-NMMA with L-arginine on the release aldosterone. Adrenal slices were superfused with medium containing KRBGA alone (control, $O$ ), Larginine ( $\boldsymbol{\Delta})$, L-NMMA ( $\square$ ) and L-NMMA with L-arginine ( $\square$ ) for $60 \mathrm{~min}$. Results are presented as the mean \pm SEM, expressed as the percentage of each basal aldosterone release at the $0 \mathrm{~min}$. ${ }^{*} P<0.05$ vs. control (baseline).

be essential for aldosterone production stimulated by ACTH. It is not likely that ACTH stimulate the production of aldosterone directly, because ACTH is able to stimulate the particulate guanylate cyclase, but not the soluble guanylate cyclase in rat adrenal gland [25]. Furthermore, Rosenberg et al. [26] reported that sodium nitroprusside inhibited ACTH-stimulated aldosterone secretion. These reports and our data may indicate that NO does not stimulate the production of aldosterone, but the process of aldosterone production stimulated by ACTH requires NO.

The increase in aldosterone release in response 


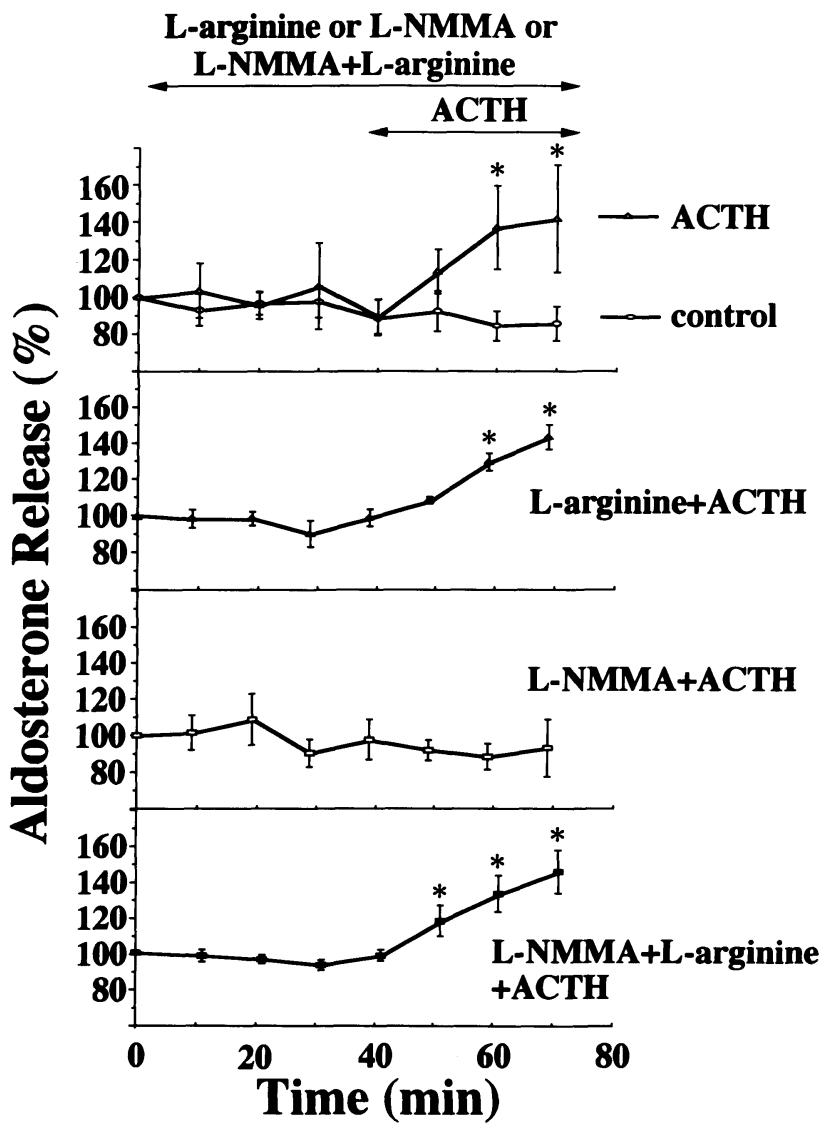

Fig. 2. Effects of L-arginine, L-NMMA and L-NMMA with $\mathrm{L}$-arginine on the release of aldosterone in response to ACTH. ACTH was added for $30 \mathrm{~min}$ after the superfusion with a medium containing KRBGA alone $(\triangle)$, L-arginine $(\boldsymbol{\Delta})$, L-NMMA $(\square)$ and LNMMA with L-arginine ( $)$ for $30 \mathrm{~min}$. Each point is the mean \pm SEM. ${ }^{*} P<0.05$ vs. control (baseline, $\bigcirc$ ).

to A II was inhibited by L-NMMA, L-arginine and L-NMMA with L-arginine. To confirm whether Larginine and L-NMMA suppressed aldosterone production directly or through the NO system, we studied the effect of L-glutamine which was not a NO donor. The increase in aldosterone release in response to A II was not inhibited by L-glutamine. The NO-cyclic GMP pathway was known to inhibit the $\mathrm{Ca}^{2+}$ phosphoinositide messenger system [27, 28], and Wink et al. [29] reported that microsomal cytochrome P450 steroidogenetic enzymes can be directly inhibited by NO. These results suggest that the NO system may inhibit aldosterone release in response to A II by the pathway of NO-cyclic GMP or by the inhibitory effect of NO on P450. Since L-NMMA inhibited aldosterone re-

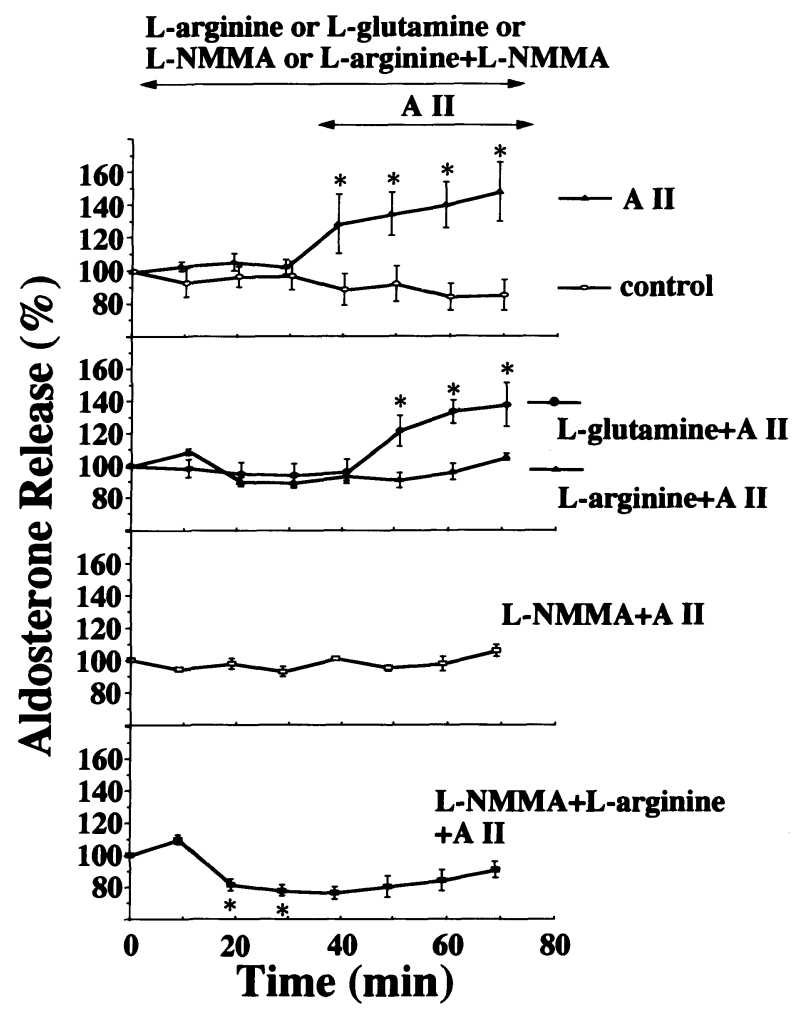

Fig. 3. Effects of L-NMMA, L-arginine, L-NMMA with Larginine and L-glutamine on the release of aldosterone in response to angiotensin II (A II). A II was added for $30 \mathrm{~min}$ after superfusion with a medium containing KRBGA alone $(\triangle)$, L-arginine $(\boldsymbol{\Delta})$, L-glutamine (O), L-NMMA ( $\square$ ) and L-NMMA with L-arginine $(\square)$ for $30 \mathrm{~min}$. Each point is the mean \pm SEM. ${ }^{*} P<0.05$ vs. control (baseline, $\bigcirc$ ).

lease in response to A II, L-NMMA may have a specific effect. This effect may make it difficult to assess the role of the NO system on the production of aldosterone stimulated by A II. Our findings may point out another possibility: that the NO system has not a major effect on the release of aldosterone in response to A II, and that L-NMMA and L-arginine directly suppress the release of aldosterone in response to A II.

Since $\mathrm{NO}$ inhibits the $\mathrm{Ca}^{2+}$ phosphoinositide messenger system $[27,28]$, the production of aldosterone via A II would be inhibited if cyclic GMP were produced by the NO system in the adrenal gland to affect aldosterone production, but our results were not consistent with this hypothesis. Our findings suggested that the NO system is involved in the release of aldosterone in response to A II, and that L-NMMA and L-arginine directly sup- 
press the release of aldosterone in response to $\mathrm{A}$ II. Cyclic GMP is a second messenger that modifies the effects of cyclic AMP. It was recently recognized to be a messenger of atrial natriuretic peptide (ANP) and NO. An increase [30], no effect [31], or a decrease [24] in aldosterone production has variously been reported, concerning the effects of cyclic GMP on steroid production following exposure to a cyclic GMP analogue. Some investigators report no effect or a decreased effect of A II stimulation on aldosterone production by a cyclic GMP analogue [31, 32]. If a NO-cyclic GMP pathway inhibits aldosterone release by A II, L-NMMA would stimulate aldosterone release, or both L-arginine and L-
NMMA may have an inhibitory effect on aldosterone production by A II. The exact reason why the basal release of aldosterone was decreased by Larginine and L-NMMA is not certain, but this effect occurred transient in periods of the 20 and $30 \mathrm{~min}$ and the level of aldosterone returned to normal after that.

In conclusion, the inhibition of NO synthesis prevented the ACTH-stimulated release of aldosterone, which suggests that $\mathrm{NO}$ is required for the action of ACTH on aldosterone production. L-NMMA and L-arginine may directly suppress the release of aldosterone in response to A II, but further studies are needed to elucidate the role of $\mathrm{NO}$ in the action of A II.

\section{References}

1. Gathwaire J, Charles SL, Chess-Williams R (1988) Endothelium-derived relaxing factor release on activation of NMDA receptors suggests role as intracellular messenger in the brain. Nature 336: 385-388.

2. Knowles RG, Palacios M, Palmer RMJ, Moncada S (1989) Formation of nitric oxide from L-arginine in central nervous system: A transduction mechanism for stimulation of the soluble guanylate cyclase. Proc Natl Acad Sci USA 86: 5159-5162.

3. Gillespie JS, Liu X, Martin W (1989) The effects of L-arginine and $\mathrm{N}^{\mathrm{G}}$-monomethyl L-arginine on the response of the rat anococcygeus muscles to NANC nerve stimulation. Br I Pharmacol 98: 1080-1082.

4. Lamas S, Marsden PA, Li GK, Tempst P, Michel T (1992) Endothelial nitric oxide synthase, molecular cloning and characterization of a distinct constitutive enzyme isoform. Proc Natl Acad Sci USA 89: 6348-6352.

5. Nishida K, Harrison DG, Navas JP, Fishier AA, Dockery SP, Uematsu M, Nerem RM, Alexander RW, Murphy TJ (1992) Molecular cloning and characterization of the constitutive bovine aortic endothelial cell nitric oxide synthase. J Clin Invest 90: 2092-2096.

6. Janssons SP, Shimouchi A, Quertermous T, Bloch DB, Bloch KD (1992) Cloning and expression of a cDNA encoding human endothelium-derived relaxing factor/nitric oxide synthase. J Biol Chem 267: 14519-14522.

7. Yui Y, Hattori R, Kosuga K, Eizawa H, Hiki K, Kawai C (1991) Purification of nitric oxide synthase from rat macrophages. J Biol Chem 266: 12544-12547.

8. Xie Q, Cho HJ, Calaycay J, Mumford RA, Swiderek KM, Lee TD, Ding A, Troso T, Nathan C (1992)
Cloning and characterization of inducible nitric oxide synthase from mouse macrophages. Science 256: 225-228 .

9. Lyons CR, Orloff GJ, Cunningham JM (1992) Molecular cloning and functional expression of an inducible nitric oxide synthase from a murine macrophage cell line. J Biol Chem 267: 6370-6374.

10. Yui Y, Hattori R, Kosuga K, Eizawa H, Hiki K, Ohkawa S, Ohnishi K, Terao S, Kawai C (1991) Calmodulin-independent nitric oxide synthase from rat polymorphonuclear neutrophils. J Boil Chem 266: 3369-3371.

11. Nunokawa Y, Ishida N, Tanaka S (1993) Cloning of inducible nitric oxide synthase in rat vascular smooth muscle cells. Biochem Biophys Res Commun 191: 89-94.

12. Jansson L, Sandler S (1991) The nitric oxide synthase II inhibitor $\mathrm{N}^{\mathrm{G}}$-nitro-L-arginine stimulates pancreatic islet insulin release in vitro, but not in the perfused pancreas. Endocrinology 128: 3081-3085.

13. Kato M (1992) Involvement of nitric oxide in growth hormone (GH)-releasing hormone-induced $\mathrm{GH}$ secretion in rat pituitary cells. Endocrinology 131: 2133-2138.

14. Palacios M, Knowles RG, Palmer RMJ, Moncada S (1989) Nitric oxide from L-arginine stimulates the soluble guanylate cyclase in adrenal glands. Biochem Biophys Res Commun 165: 802-809.

15. Imai T, Hirata Y, Marumo M (1992) Expression of brain nitric oxide synthase mRNA in various tissues and cultured cells of rat. Biomed Res 13: 371-374.

16. Sessa W, Harrison J, Luthin D, Pollock J, Lynch K (1993) Genomic analysis and expression patterns reveal distinct genes for endothelial and brain nitric oxide synthase. Hypertension 21: 934-938. 
17. Bredt DS, Hwang M, Snyder SH (1990) Localization of nitric oxide synthase indicating a neural role for nitric oxide. Nature 347: 768-770.

18. Adams ML, Nock B, Truong R, Cicero TJ (1992) Nitric oxide control of steroidogenesis: Endocrine effects of $\mathrm{N}^{\mathrm{G}}$-nitro-L-arginine and comparisons to alcohol. Life Science 50: PL-35-PL-40.

19. Hishikawa K, Nakaki T, Tsuda M, Esumi H, Oshima H, Suzuki H, Saruta T, Kato R (1991) Effect of systemic L-arginine administration on hemodynamics and nitric oxide release in man. Jpn Heart J 33: 4148.

20. Franco-Saenz R, Suzuki S, Tan SY, Mulrow PJ (1980) Prostaglandin stimulation of renin release: Independence of $\beta$-adrenergic receptor activity and possible mechanism of action. Endocrinology 106: 1400-1404.

21. McKenzie JK, Clements JA (1974) Simplified radioimmunoassay for serum aldosterone utilizing increased antibody specificity. J Clin Endocrinol Metab 38: 622-627.

22. Lowry $\mathrm{OH}$, Rosebrough NJ, Farr AL, Randall RJ (1951) Protein measurement with the folin phenol reagent. J Biol Chem 193: 265-275.

23. Kojima I, Kojima K, Rasmussen H (1985) Role of calcium and cAMP in the action of adrenocorticotropin on aldosterone secretion. J Biol Chem 260: 4248-4254.

24. McFarland RT, Zelus BD, Beavo JA (1991) High concentrations of a cGMP-stimulated phosphodiesterase mediate ANP-induced decreases in cAMP and steroidogenesis in adrenal glomerulosa cells. $J$ Biol Chem 266: 136-142.

25. Nambi P, Sharma RK (1981) Adrenocorticotropic hormone-responsive guanylate cyclase in the particulate fraction of rat adrenal glands. Endocrinology 108: 2025-2027.

26. Rosenberg J, Pines M, Huewitz S (1988) Regulation of aldosterone secretion by avian adrenocortical cells. J Endocr 118: 447-453.

27. Ramagopal MV, Leighton HJ (1989) Effects of $\mathrm{N}^{\mathrm{G}}$-monomethyl-L-arginine of field stimulation-induced decreases in cytosolic $\mathrm{Ca}^{2+}$ levels and relaxation in the rat anococcygeus muscle. Eur J Pharmacol 174: 297-29.

28. Barrett $P Q$, Isales CM (1988) The role of cyclic nucleotides in atrial natriuretic peptide-mediated inhibition of aldosterone secretion. Endocrinology 122: 799-808.

29. Wink DA, Osawa Y, Darbyshire JF, Jones CR, Eshenaur SC, Nims RW (1993) Inhibition of cytochromes $\mathrm{P} 450$ by nitric oxide and a nitric oxide-releasing agent. Arch Biochem Biophys 300: 115-123.

30. Vinson GP, Whitehouse BJ (1982) Effects of stimulation on the steroid profile formed by rat adrenal capsule tissue incubated in vitro. J Steroid Biochem 17: 159-164.

31. Ganguly A, Chiou S, West LA, Davis JS (1989) Atrial natriuretic factor inhibits angiotensin-induced aldosterone secretion: Not through cGMP or interference with phospholipase C. Biochem Biophys Res Commun 159: 148-154.

32. Barrett $P Q$, Isales CM (1988) The role of cyclic nucleotides in atrial natriuretic peptide-mediated inhibition of aldosterone secretion. Endocrinology 122: 799-808. 